\title{
La familia en el ordenamiento jurídico peruano
}

\author{
por el Dr. DOMINGO GARCIA RADA \\ Vocal de la Corte Superior de Lima, \\ Catedrático Titular de Derecho Procesal Civil \\ en la Pontificia Universidad Católica del Perú.
}

En la Constitución Nacional vigente desde abril de 1933, en el Título de Garantías Constitucionales, se encuentran dos artículos referentes a la familia:

"Ârt. 51\%_El matrimonio, la familia y la matemidad están bajo la protección de la ley".

"Art. 52\%-Es deber primordial del Estado la defensa de la salud física, mental y moral de la infancia. El Estado defiende el derecho del niño a la vida del hogar, a la educación, a la orientación vocacional y a La amplia asistencia cuando se halle en situación de abandono, de enfermedad o de desgracia. El Estado encomendará el cumplimiento de lo dispuesto en este artículo a organismos técnicos adecuados".

Es importante que la Carta Magna del Perú reconozca la trascen. dencia de la familia que precede a la sociedad civil y política y es más completa que ambas. Desgraciadamente, entre nosotros la familia no es institución que esté compenetrada con el pueblo peruano. No puede hablarse de crisis, sino más bien, que no ha llegado $\alpha$ constituirse de manera definitiva. No hay el sentido de familia. El hogar no se respeta. Especialmente en el pueblo, la familia se reduce a la unión sexual del hombre y de la mujer, destinada a procrear hijos y a ayudarse en el trabajo, pero sin darle el carácter permonente y definitivo que está en su esencia.

En esta situación, era muy necesario que la familia legalmente constituída fuera indisoluble. Pero la misma Asamblea Constituyente que estableció los artículos anteriores, dispuso que las leyes 6889 y 6890 -que establecían el divorcio absoluto $y$ el matrimonio civil- quedasen incorporadas en el nuevo Código Civil, cuyo proyecto no reconocía el divorcio absoluto. Así resulta que entre nosotros con tantos factores de disgregación familiar $y$ donde el matrimonio es poco frecuente en las clases populares, existe el divorcio absoluto que disuelve el vínculo contraído por esta minoría. Puede decirse que, en el caso del Perú, el divorcio es una eficiente causa de disgregación nacional. 71 a 83).

La Educación es tratada en el Título III de esta Constitución (Ārts. 
Los artículos que componen este Título son los siguientes: tado.

Art. 71\%-La dirección técnica de la Educación corresponde al Es-

Art. $72^{\circ}$ - La enseñanza primaria es obligatoria y gratuita.

Art. $73^{\circ}$-Habrá, por lo menos, una escuela en todo lugar cuya po blación escolar sea de treinta alumnos.

Art. 74-Las escuelas que funcionen en los centros industriales, agrícolas o mineros, serán sostenidas por los respectivos propietarios o empresas.

Art. $75^{\circ}-$ El Estado fomenta la enseñanza en sus grados secundario y superior, con tendencia a la gratuidad.

Art. $76^{\circ}$-En cada departamento habrá, por lo menos, una escuela. de orientación industrial.

Art. 77-El Estado fomenta la enseñanza técnica de los obreros.

Art. 78:-El Estado fomenta y contribuye al sostenimiento de la educación pre-escolar y post-escolar y las escuelas para niños retardados o anormales.

Art. 79\%-La educación moral y cívica del niño es obligatoria $y$ se inspirará necesariamente en el engrandecimiento nacional y la solidaridad humana.

Art. $80^{\circ}$ - El Estado garantiza la libertad de cátedra.

Art. 81-El profesorado es carrera pública y da derecho a los goces que fija la ley.

Art. 82\%-Los tesoros arqueológicos, artísticos e históricos están bajo Ia salvaguardia del Estado.

Art. $83^{\circ}$-La ley señalará el monto mínimo de la renta destinada al sostenimiento y difusión de la enseñanza y la proporción en que anualmente debe aumentarse.

Del estudio de este articulado, resultan algunas conclusiones:

No hay monopolio de la enseñanza. El Estado puede trazar las normas generales sobre este Ramo, v. g. años de estudio, materias básicas, locales escolares, etc., pero existe libertad en lo demás. Respetando las normas generales, cada colegio puede establecer las que crea convenientes. El Estado mantiene colegios dejando campo a la iniciativa particular para establecer escuelas privadas. Eso permite a los padres de familia escoger el colegio que deseen.

La enseñanza primaria es obligatoria. En las condiciones actuales de vida humana, es indispensable un mínimo de cultura para que el hombre pueda desarrollarse como persona y llegar a ser ciudadano consciente de sus deberes y responsabilidades. El sentido de responsabilidad frento a su familia y a su patria solamente puede desenvolverse mediante la cul. tura y su base es la educación primaria. Siendo ésta gratuita está al alcance de todos.

Se rodea de dignidad al maestro, garántizóndose su libertad de cá. tedra, lo que generalmente ha sido respetado. Se declara carrera pública el magisterio, concediéndole goces. Como veremos, existe el Escalafón Magisterial para los ascensos y promociones.

En cuanto al haber del profesor, se nota apreciable mejoría en estos 
últimos años, garantizándose su pago puntual, mediante el empoce anticipado del haber en una entidad semi-tiscal como es la Caja de Depósitos y Consignaciones.

La actitud del Estado es coadyuvar con la iniciativa privada en el establecimiento de escuelas. Por eso en estos artículos se habla de "fomento de la enseñanza" por parte del Estado, mediante subsidios cuando los colegios particulares lo requieran y concediéndoles facilidades. Trmbién queda obligado a establecer colegios por su cuenta.

Aunque coloca como fundamento de la enseñanza del niño "el engrandecimiento nacional y la solidaridad humana", sin embargo -como veremos más adelante- la Ley de Educación vigente dice que la enseñanza debe ser democrática, nacionalista, humana y cristiana, claro reconocimiento a los sentimientos mayoristas de la población peruana. También en el Plan Nacional de Educación se reconoce que la labor que realiza la Iglesia Católica es superior a "las de cualquier otra institución no oficial".

El Código Civil Peruano - vigente desde noviembre de 1936- consta de Cinco Libros; en el Segundo se ocupa "Del Derecho de Familia", dividido en siete secciones. Examinaremos cinco, dejando aparte lo referente al régimen de bienes y a la curatela.

La primera sección comienza con los Esponsales, promesa de matrimonio que obliga, siempre que conste de manera indubitable (Art. 75).

Trata luego de los Impedimentos Matrimoniales, dividiéndolos en generales y especiales, según imposibilite el matrimonio en general o con determinada persona. Entre los generales: la edad mínima para poder contraer matrimonio válido, en hombres y mujeres, es de 18 años (Art. 82 inc. I). Una ley posterior rebaja la edad a 16 y 14 años, respectivamente. Es impedimento la enfermedad mental "aunque tengan intervalos lúcidos" (íd., inc. 2\%); la enfermedad crónica contagiosa, transmisible por herencia "que constituya peligro para la prole" (íd. inc. 39); los sordomudos "que no supieren expresar su voluntad de manera indubitable" (íd. inc. 4\%), y los casados.

Los impedimentos especiales o nupciales se refieren al parentesco natural o legal y a dos situaciones más: "el condenado como partícipe en la muerte de uno de los cónyuges" y "el raptor con la raptada, mientras ésta se halle en su poder" (Art. 83 , inc. $4^{\circ}$ y $5^{\circ}$ ).

Como impedimento que hace el matrimonio ilícito -pero no nulo ni anulable- el Código en su Art. 84 prohibe el matrimonio del tutor con el menor" durante el ejercicio del cargo ni antes que estén judicialmente aprobadas las cuentas de la administración" Y sanciona esta infracción con la pérdida de la retribución que "le habría correspondido sobre los bienes del menor".

El nuevo matrimonio del viudo requiere inventario previo de los bienes de sus hijos o declaración jurada de que carecen de ellos; y el que se casare sin observar esta disposición "perderó el usufructo que le corresponde sobre los bienes de sus hijos (Art. 86).

Para evitar confusión en la descendencia, "La viuda no podrá contraer matrimonio, sino pasados 300 días de la muerte de su marido, salvo que diere a luz", sancionando esta omisión con la pérdida de los bienes del marido. 
Para contraer matrimonio, los menores de edad necesitan del consentimiento expreso de sus padres, a falta de éstos sus ascendientes más próximos, y si no, deberá darlo el Consejo de Familia. Los hijos adoptivos requerirón del consentimiento de sus padres naturales $\mathrm{y}$ el del adoptante. Para los expósitos, se requiere el consentimiento de los directores de las: establecimientos que los amparan. Si el menor se hallare bajo la potestad del Juez de Mencres, éste deberá dorlo. Los hijos ilegítimos requerirán del permiso de quien lo hubiera reconocido como tal (Arts. 89 al 95).

En cuanto a la formalidad, el consentimiento deberá constar por instrumento público (Art. 96).

Contra el disenso de los padres y ascendientes, no cabe recurso alguno. Contra la negativa del Consejo de Familia, los menores pueden solicitar licencia judicial, la cual "se dictará sin expresión de fundarmentos y es inapelable" (Art. 99).

Si el menor se casare sin obtener el consentimiento "no gozará de la posesión y administración de sus bienes, hasta que sea mayor de edad". Tendrá en este caso derecho a una pensión alimenticia. (Ârt. 100).

De la Celebración del Matrimonio se ocupa el Título IV, y el Ārt. 101 de la comprobación de la capacidad de los contrayentes, indicando los documentos que la acrediten. Sólo el Juez podrá dispensar de la presentación de algunos de estos documentos, cuando existan causas que así lo' justifiquen. (Ârt. 102).

El anuncio del matrimonio deberá hacerse en edictos que se publicarán por periódico. Deberá consignar los datos que sirvan para identificar al contrayente. (Art. 103). Puede dispensarse de su publicación, por orden del Alcalde (Art. 105).

La oposición al matrimonio se presentará ante la Municipalidad y si tuviere fundamento legal, se remitirá al Juez (Art. 107); si careciere de este fundamento el Alcalde la rechazará de plano. El Ministerio Fiscal puede oponerse, si tuviere conocimiento de alguna causal de nulidad absoluta: la ley concede esta facultad a cualquiera que supiere del impedimento (Arts. 108 y 109).

De no existir oposición, transcurrido el plazo de ley, el Alcalde declarará la capacidad de los contrayentes (Art. 112); esta declerración tiene validez durante cuatro meses. Si no resultare acreditada la capacidad, remitirá lo actuado al Juez, quien en breve plazo, oyendo al Ministerio Fiscal, resolverá lo conveniente (Ärt. 113).

La ceremonia del matrimonio se realizará en la Municipalidad, en presencia de dos testigos. (Arr. 114). El Alcalde puede delegar esta función en el Teniente Alcalde, Oficiales de Registro, Ägentes Municipales, Directores o Jefes de Hospitales, Capellones y Misioneros Católicas (Art. 115). Como excepción, el matrimonio podrá celebrarse fuera del local municipai' (Art. 117). El matrimonio puede celebrarse por poder, exigiéndose que éste sea en escritura pública, indicándose el nombre de la persona con quien debe contraerse. (Art. 118). Fn inminente peligro de muerte, el matrimonio puede celebrarse sin las formalidades de ley $y$ ante el párroco o sacerdote, pero no surtirá́ efectos civiles si se contrae entre incapaces. (Är. 120). El párroco o sacerdote delegado puede celebrar matrimonio civil, con la 
exigencia de la inmediata remisión del acta $\alpha$ la oficina del Registro más próximo y mientras no se inscriba, no producirá efectos civiles; en este caso de excepción la capacidad se acreditará ante el referido sacerdote o párroco, observando las formalidades del Código (Arts. 124 a 126).

La prueba del matrimonio es la partida del Registro Civil. (Ant. 127). Es la prueba legal por excelencia, documento público cuya validez subsiste mientras no se anule en juicio ordinario. Pero agrega este artículo: "Justificada la falta o pérdida del registro, es admisible cualquier otro medio de prueba". Esta es la partida del matrimonio religioso, prueba subsidiaria aceptada por los tribunales. La posesión constante de estado de casado, subsana cualquier "defecto de forma de ésta" (Ârt. 128). Si a la pasesión se agrega que las partidas de los hijos indican que éstos son legítimos, la presunción adquiere mayor fuerza (Art. 129). Como resultado de un juicio penal, "la inscripción de la sentencia tendrá la misma fuerza probatoria que la partida". (Ārt. 130). En caso de duda, la posesión del estado de matrimonio decidirá en favor de los cónyuges, la celebración del matrimonio. (Ärt. 131).

En cuando a la nulidad, el Código distingue entre matrimonio nulo y anulable. Es nulo el realizado por quienes no pueden contraerlo y anulable, entre quienes no pueden casarse entre sí. (Ârt. 132). También es nulo el celebrado sin la intervención del funcionario competente. La acción sólo pueden intentarla quienes tengan "interés legítimo y actual" y el Ministerio Público. (Art. 134). El matrimonio anulable proviene de haberlos con. traído quienes están impedidos transitoriamente por razón de edad o de estado, como es el caso del raptor con la raptada, hallóndose èsta en su poder (Art. 142). En este caso el matrimonio convalida con el transcurso del tiempo y por la confirmatoria de los cónyuges al llegar a su mayoría, la que tiene efecto retroactivo. (Art. 144). La impotencia absoluta es causal de anulabilidad, pero la acción corresponde únicamente a los cónyuges. (Ât. 145). Esta causal es de anulabilidad y no de nulidad, porque, además de la procreación, existen otros fines en el matrimonio, los cuales se pueden cumplir aunque ella exista. Igualmente es anulable, si uno de los cónyuges "por causa pasajera no hubiese estado en el pleno ejercicio de sus facultades mentales al tiempo de contraerlo". (Art. 146).

También es anulable cuando se ha contraído el matrimonio por "error sobre la identidad del otro contrayente, o por ignorancia de algún defecto sustancial del mismo que haga la vida común insoportable" (Ârt. 147). En ambos casos la vida matrimonial posterior convalida la unión. Es, asimismo, anulable el contraído mediante violencia o grave amenaza (Art. 148) que se refiera a la persona, o a parte considerable de los bienes. EI Código establece que "sólo el cónyuge perjudicado" puede pedir la nulidad en los casos anteriores, siempre que no hubiere hecho vida común "durante seis meses después de desaparecida la causa" (Art. 149). La acción prescribe a los dos años de celebrado el matrimonio. Pasado este plazo, la unión se convalida desapareciendo el motivo de anulabilidad.

Existe una tercera clase de matrimonios: el ilícito, cuando se ha celebrado entre "personas a quienes la ley les prohibe celebrarlo por causa 
de adopción". Es ilícito, pero no nulo ni anulable, pues la adopción cesa: y el matrimonio es válido (Ârt. 150).

La acción de nulidad es personal, no pasa a los herederos del cónyuge, pero sí podrán continuar la demanda entablada por su causante. (Art. 151). El matrimonio declarado nulo produce efectos civiles si se contrajo de buena fe; si hubo mala fe en uno de los cónyuges, para él no hay efectos civiles (Art. 157). Puede señalarse indemnización en concepto de "reparación del daño moral" (Art. 156).

El Título VII se ocupa de los "Deberes y Derechos que nacen del matrimonio". Estos son: fidelidad y asistencia reciproca entre los cónyuges (Ârt. 159); alimentar y educar a los hijos (Ârt. 158); hacer vida en común en el domicilio conyugal (Ârt. 160). Al marido corresponde dirigir la sociedad conyugal, debiendo fijar el domicilio común. Es obligación del marido. "suministrar todo lo necesario para la vida del hogar". Esta obligación cesa, si la mujer abandona el hogar y rehusa volver a él (Arts. 161 a 165). El marido es el representante de la sociedad económica que resulta del matrimonio, pero la mujer tiene la representación para los gasios ordinarios; si se excede en los gastos, en forma desproporcionada, el Juez puede privarla de ello. (Art. 168 a 170). La mujer lleva el apellido del marido, agregado al suyo. (Ant. 171). La mujer puede comparecer en juićio y disponer libremente de sus bienes propios (Art. 172). Ha desaparecido la antigua incapacidad de la mujer. Hoy es capaz, con las limitaciones inherentes a su estado de casada. Puede ejercer cualquier oficio, profesión o industria con consentimiento del marido, pero si éste lo negare puede recurrir al Juez (Art. 173). Como excepción y en ciertos casos -interdicción del marido, ausencia o detención a pena privativa de la libertad-, "la mujer asume la dirección y representación de la sociedad conyugal" (Art. 174). La mujer no respande con suis bienes propios de las "deudas personales del marido". (Art. 175).

La Sección Tercera de este Libro Segundo, se ocupa del divorcio. La Comisión Reformadora del Código Civil de 1852, formada por notables juristas, estimó necesario mantener la indisolubilidad del vínculo matrimo. nial. El ponente del Libro, Dr. Pedro M. Oliveira - Catedrático y Rector de la Universidad de San Marcos y Ministro de Educación en varias oportunidades- hociendo un profundo estudio del divorcio, concluyó que era institución destructora de la familia; que ésta era la base de la nacionalidad que convenía tonificar; que la experiencia en Francia demostraba que el divorcio, lejos de disminuir, cumentaba en proporción geométrica y que en el caso del Perú, donde el matrimonio tenía poco arraigo, especialmente en la clase popular, constituiría un suicidio disolver las uniones bien constituídas. Esta Ponencia presentada por quien era autoridad en el campo del Derecho, fué decisiva y la Comisión presentó el Anteproyecto con el Matrimonio indisoluble. El mismo Congreso que había redactado la Constitución que declaraba que la Familia estaba protegida por la ley, dispuso que una Comisión Revisora, incorporara el Matrimonio Civil y el Divorcio dentro del articulado del Proyecto de Código. Assí se destruyó la unidad del Código Civil. La separación de cuerpos que, como su modelo del De. 
recho Canónico, era institución definitiva, se convirtió en antesala del divorcio, como veremos luego.

El divorcio tiene antecedentes en el Perú. Recién proclamada la independencia, el Presidente de la Corte Suprema, don Manuel Lorenzo de Vidaurre, presentó un proyecto de Código Civil. A pesar de ser partidario del divorcio absoluto, mantuvo el matrimonio indisoluble, porque estimó que a los pueblos no se les dan instituciones que les son extrañas $y$ que el Perú rechazaba tal situación. En 1845 se nombró una Comisión para que redactara el Código Civil, porque el Proyecto de Vidaure no había merecido sanción oficial. La Comisión se dividió al tratar del Matrimonio y después de varios años, don Andrés Martínez logró imponer el Matrimonio conforme al Concilio de Trento. Este Código rigió de 1852 a 1936. En la Asamblea Nacional de 1920, volvió a presentarse un proyecto de ley estableciendo el Divorcio Absoluto y el Matrimonio Civil, aprobado en ambas Cámaras, pero vetado por el Presidente de la República. Con la Re. volución de 1930, la Junta Militar retiró el veto y publicó las Leyes números 6889 y 6890, estableciendo ambas instituciones. Fueron estas leyes lais incorporadas por la Comisión Revisora con la sola modificación de que el matrimonio civil no era obligatorio previo al religioso, pudiendo celebrarse cntes o después.

Las causales de divorcio son: adulterio, sevicia, atentado contra la vida del cónyuge, injuria grave, abandono malicioso que dure más de dos años, conducta deshonrosa que haga insoportable la vida en común, uso habitual de estupefacientes, enfermedad venérea contraída después de celebrado el matrimonio, condena a pena privativa de la libertad, mayor de dos años, impuesta después del matrimonio y el mutuo disenso (Ārt. 247).

El mutuo disenso no origina propiamente el divorcio absoluto, sino la separación de cuerpos, pero transcurrido un año de dictada la sentencia, cualquiera de los cónyuges puede pedir el divorcio y por la constatación del plazo, el Juez lo declara. Por eso es que el Mutuo Disenso ha convertido a la Separación de Cuerpos en un medio para lograr el divorcio ahsoluto sin causal.

Ninguno de los cónyuges puede fundar el divorcio absoluto en hecho propio. (Art. 249). El divorcio disuelve el vínculo matrimonial. (Ârt. 253). Los hijos se conficrón al cónyuge inocente (Art. 255), pero si ambos fueren culpables, es el juez el llamado a resoiver a quién se los confía, pudiendo entregarlos a sus ascendientes. Como regla general, el Código ordena que los hijos mayores de 7 años sean entregados al padre y las hijas a la madre. pero siempre es el Juez quien determinará lo que mejor convenga. (Art. 256). El padre está obligado a alimentar a sus hijos, contribuyendo la madre en forma proporcional. (Art. 258). Con el divorcio, terminan los deberes de lecho y habitación, no hay alimentos, salvo que uno de ellos caiga en indigencia. en cuyo caso el otro está obligado a pasarle una pensión, aunque sea quien dió el motivo para el divorcio. (Art. 263). Aquí vemos que subsiste la obligación moral creada por razón del vínculo del matrimonio. Cesan los derechos hereditarios y el cónyuge culpable pierde los gananciales. (Arts. 265 y 266).

El Título último de esta Sección contiene un solo artículo: "Las dis- 
posiciones de la ley, en lo concerniente al matrimonio, no se extienden más allá de sus efectos civiles, dejando íntegros los deberes que la religión impone". (Art. 292). Este artículo no existía en el Proyecto, porque el matrimonio era indisoluble. Es la concesión al credo religioso de la mayoría de los peruanos. Este artículo ha servido de fundamento a una ejecutoria de la Corte Suprema estableciendo que "No obstante haberse contraído matrimonio civil, no está obligado el marido a dar alimentos a la mujer que se niega a hacer vida común mientras no se realice el matrimonio religioso". Como fundamento se expuso que mientras el marido no cumpliera con su promesa de realizar el matrimonio religioso, la mujer no estaba obligada $\alpha$ hacer vida común, pero no existiendo ésta, no había obligación de alimentos, porque éstos suponen la asistencia recíproca y vida común de los cónyuges. Es obligación correlativa. Esta ejecutoria suprema constituye un reconocimiento expreso del matrimonio religioso ignorado por la ley civil.

En cuanto a las Relaciones de Parentesco -Sección Cuarta- nuestro Código reconoce tres clases de hijos: Legítimos, los nacidos dentro del matrimonio (Art. 299) y legitimados por subsiguiente matrimonio por declaración judicial (Art. 314); Ilegítimos, los nacidos fuera del matrimonio (Art. 348), involucróndose en esta forma los naturales, adulterinos, etc.; Adoptivos, parentesco civil que consiste en introducir dentro del matrimonia como legítimo a quien no lo es, pero con observancia de los requisitos que señala el Art. 326.

Es posible, dentro de ciertas circunstancias, impugnar la paternidad (Art. 301), como existe la presunción juris de que todo hijo nacido dentro del matrimonio tiene por padre al marido, se requiere prueba plena que acredite lo contrario. La madre no puede negar su maternidad, hecho físico que cae bajo la acción de los sentidos y su declaración contra la legitimidad de su hijo, no vale. (Ârt. 300). La acción del hijo para pedir su filiación, es imprescriptible (Art. 308), en cambio, el padre tiene 90 días para impugnar el nacimiento de quien presume no ser su hijo.

La legitimación puede operorse por subsiguiente matrimonio de los padres, siempre que éstos no tengan impedimento; $y$ por declaración judicial (Ârt. 314). En este último caso la ley exige condiciones precisas (Art. 319). Cualquier hijo ilegítimo puede ser legitimado. La acción se sigue ante la Corte Superior en pleno, la que actúa en única instancia. (Art. 322). El efecto de la legitimación es equiparar a los hijos legitimados con los legítimos (Arts. 317-323).

La adopción es irrevocable y no admite modalidad alguna (Art. 328). El adoptado conserva los derechos $\mathrm{y}$ deberes de su familia natural, pera. al convertirse en hijo del adoptante, cae bajo su patria potestad. (Art. 335). También es su heredero, pero el adoptante no hereda al adoptado sino por testamento. (Art. 338). Hay adopción menos plena consistente en alimentar y educar al adoptado (Ärt. 344); termina al llegar a su mayoría de edad o cuando pudiere ganarse la vida con su trabajo (Art. 347).

La filiación ilegítima se establece por el hecho del nacimiento (Art. 349). Ei reconocimiento puede hacerse por escritura pública en el registro de estado civil o por testamento. (Art. 354). La paternidad ilegítima puede 
ser judicialmente declarada cuando existen pruebas indubitables de este hecho. La sentencia que la declara tiene los mismos efectos que el reconocimiento expreso. (Art. 388).

La Patria Potestad - deber y derecho- se confiere a los padres (Art. 390); en caso de disentimiento, prevalece la voz del padre. (Art. 391). El representante legal $y$ el administrador de los bienes del hijo, será el padre (Art. 392), de la misma manera que es el jefe de la familia. Cuando se trata de hijos ilegítimos, la ejerce el padre si han sido reconocidos voluntariamente por él. (Art. 394), de lo contrario, corresponde a la madre. (Art. 395). El Art. 393 señala los deberes y derechos que la Patria Potestad otorga a los padres. Ácaba, de manera natural, por la mayoría de edad del hijo; de modo violento por muerte del padre o incapacidad; y de modo legal por adopción del hijo por otra persona, quien a su vez adquiere la Patria Potestad. (Art. 425). En ciertos casos (Art. 428) los padres pueden ser privados por el Juez de la Patria Potestad. Hay suspensión de la Patria Potestad (Art. 434) cuando los impedimentos no son definitivos, sino temporales.

De los Alimentos se ocupa el Título VII. Comprenden lo indispensable para el sustento, habitación, vestido, educación y asistencia médica. Dura hasta los 18 años, salvo que el menor siga con éxito una carrera profesional o no pueda adquirirlos por su propio esfuerzo. (Ârts. 439 y 440). Es obligación a cargo de los padres, ascendientes, descendientes y hermanos. (Ârt. 442). La cuantía la fijaró el Juez "en proporción a la necesidad del que los pide y a la posibilidad del que debe darlos". (Ârt. 449). Esta pensión puede variarse cuando cambien las circunstancias del menor o del obligado (Art. 450). Es derecho intransmisible, irrenunciable e incompensable. (Art. 454). Finalmente, esta Sección se ocupa del Bien de Familia que consiste en destinar un predio con el carácter de "Hogar de Familia" para su propia vivienda; debe constituirse por escritura pública o testamento $y$ es inembargable. Requiere aprobación judicial y que no exista oposición de terceros, cuyas acreencias sean burladas. El Hogar de Familia no puede ser enajenado, hipotecado ni arrendado. (Arts. 456 a 473).

"Al menor que no esté bajo la Patria Potestad, se le nombrará tutor que cuide su persona y bienes", dice el Art. 474. Existen las siguientes clases de tutelas: testamentaria, la proveniente de testamento o escritura pública (Art. 475); legítima, la desempeñada por los abuelos y demás ascendientes, en el orden establecido por el Art. 480, la dativa, cuando el tutor es un extraño designado por el Consejo de Familia, que debe ser ratificado cada dos años por el mismo Consejo. (Arts. 482 y 484). Estas tutelas funcionan una en defecto de la otra, teniendo preferencia, como es natural, la primera sobre la segunda y ésta sobre la tercera. Existe una última clase: la del Estado sobre los expósitos que se encuentran bajo su amparo en algún establecimiento de beneficencia, comprendiéndose también a los particulares cuando sean ellos quienes amparen a menores sin padres. El Código se ocupa luego de las personas inhábiles para ser tutores, v.g., los menores de 21 años; quienes pueden excusarse, v.g., las mujeres; del ejercicio de la tutela, la garantía que se requiere y el discernimiento de la misma; y el término de la tutela, bien sea por acabamiento 
de la tutela, como es el caso de la muerte del menor, por la cesación de la tutela como es la muerte del tutor, o por la remoción del tutór, si ésté ha causado perjuicios al menor en su persona o bienes. (Ärts. 490 al 453). Finalmente, queda por estudiar: el Consejo de Familia. Esta Institución tiene como objeto "velar sobre la persona e intereses de los menores $\mathrm{Y}$ de los incapaces mayores de edad que no tengan padre ni madre". (Art. 615).

A petición de cualquier familiar, del Ministerio Público, de un extraño o del tutor, es convocado por el Juez de Paz, citando $\alpha$ los parientes más cercanos. Existen los miembros natos (hermanos, la madre si no tuviere la administración de los bienes del menor, etc.) y faltando parientes, se llamará a los amigos. El Consejo tiene muchas atribuciones (A.rt. 644), como es nombrar tutor dativo, removerlo, aceptar herencia a favor del menor, etc. De sus resoluciones cabe apelación ante el Juez (Art. 645). Se sientan actas de sus sesiones. (Art. 648). Acaba en los mismos casos que la tutela (Art. 655).

El Código Penal - vigente desde julio de 1924- en el Libro Segundo tiene la Sección Cuarta destinada a los Delitos contra la Familia. Considera como tales a los siguientes:

Adulterio: Castiga al cónyuge y su cómplice con prisión no mayor de seis meses; reserva la acción penal únicamente al ofendido $\mathrm{y}$ como requisito exige que éste previamente haya pedido el divorcio por adulterio. No puede denuncior el delito si consintió en el hecho, o perdonó al autor o antes lo había abandonado. (Art. 212). Es uno de los pocos casos en que la acción penal se reserva al agraviado, siendo lo común que la denuncia pueda entablarla el Ministerio Público, el agraviado, etc. Se comprende esta excepción por la noturaleza reservada de este delito. Interesa destacar el requisito de haber iniciado el divorcio, de manera que basta presentar la demanda por esta causal para poder denunciar criminalmente el mismo hecho.

En cualquier momento el cónyuge ofendido puede perdonar al otro, bien sea de manera expresa o uniéndose nuevamente con él; en estos casos se produce la remisión de la pena. (Art. 213).

Matrimonio Ilegal: "El que siendo casado contrajera nuevo matrimonio será reprimido con prisión no mayor de cuatro años ni menor de un año" (Art. 214). No dice qué clase de matrimonio. Existen ejecutorias contradictorias, pero prevalece el criterio de que en materia penal lo importante es saber la intención y ésta se manifiesta en cualquier matrimonio. Supresión y alteración del estado civil. "La mujer que fingiere preñez - parto para dar a un supuesto hijo derechos que no le corresponden, sufrirá prisión no mayor de cuatro cuños ni menor de un año". (Art. 217). A la obstetriz que colabore en el hecho se le sanciona. También configura este delito la ocultación de un niño o la atribución de falsa filiación. Es decir, toda alteración en el estado de familia.

Sustracción de Menores: "El que sustrajere un menor o rehusare entregarlo a sus padres, a su guardador o a otra persona encargada de su custodia..." comete este delito que se reprime con pena de prisión. (Art. 
220). También comprende este delito cuando se induce $a$ un menor $\alpha$ fugarse de casa de sus padres.

El Título XVIII del Libro Primero de este Código se refiere al "Tratamiento de menores" que delinquen o se encuentran en estado peligroso. En los artículos 137 al 149 se ocupa de las investigaciones que se practicarón para establecer el estado familiar y social del menor. Su edad influye en la represión y cambia sustancialmente la medida a dictarse. Si el menor tiene más de 18 años, pero menos de 21, cae bajo la jurisdicción de los tribunales comunes, pero la pena se rebaja por la mitad y solamente puede imponérsele prisión.

En su Art. 410, este Código dispone la organización de un Juzgado de Menores, compuesto de un Juez, un médico y un secretario que actuará una investigación y dictará la medida para los casos de delito, conocerá del asunto dictando la decisión de una Sala Civil. En estos procesos no hay publicidad, evitándose que el nombre del menor aparezca en los pe. riódicos. Requisito esencial para ser Juez de Menores es ser casado, con hijos y observar conducta irreprochable. La ley 8606, de diciembre de 1937, dispone que los Juzgados de Menores ejercerán las atribuciones tutelares que la ley concéde a los jueces de paz en el Código Civil.

El Decreto Supremo de julio de 1937 dicta algunas disposiciones sobre servicio doméstico: así ordena que la eonducción de menores de 16 años del lugar de su residencia a lima, debe ser con permiso de sus padres o guardadores y autorizado por el Juez de Menores y éste lo vigilará en el lugar de su residencia, debiendo las empresas de transportes avisa: a la policía cuando conduzcan menores de edad.

El Código trata de la Sociedad Especial de Patronato de Menores de Lima y, por Decreto Supremo de febrero de 1945, se dictó el Reglamento que la organiza. Colaborará estrechamente con los Jueces de Menores, vigilando a los menores, velando por su salud física y espiritual, constatando las condiciones de los hogares dónde van a ser colocados, etc.

En cuanto a los lugares de detención, existe el Hogar Infantil para la reclusión de los niños hasta los 14 años y el Reformatorio de Menores de Maranga para los menores de 14 a 18 años. Están bajo la dirección de Congregaciones Religiosas. Cuando el menor de 18 a 21 delinque, va a la cárcel, se le coloca en lugar separado de los otros reos.

La Ley Orgánica de Educación de $1^{\circ}$ de abril de 1941, contiene principios relacionados con la Familia que conviene destacar.

En el Título III, "De la Educación", se encuentra el Art. 93, que dice: "La educación estará informada por el espíritu de doctrina cristiana". Esta declaración es importante porque orienta la educación nacional. Dado su carácter imperativo, puede servir para pedir la derogatoria de cualquier disposición que la contradiga.

Luego el Art. 95 declara: "La educación religiosa es obligatoria en todos los establecimientos de enseñonza primaria y secundaria", autorizándose a las no católicos para eximirse de ella, siempre que, por escrito lo soliciten el padre o apoderado. Para dar cumplimiento a esta disposición, el nombramiento de los profesores de religión se hace de acuerdo con la autoridad eclesiástica. 
La educación primaria se realiza en dos ciclos: primero y segundo, siendo este último de mayor calidad intelectual. Ambos son obligatorios y deberón hacerse en locales separados. (Art. 162). Las escuelas de primer grado deberán existir en todos los pueblos que tengan más de 30 alumnos (Art. 155) y las de $2^{\circ}$ grado en las capitales de provincias, con asistencia regular de más de cuarenta niños (Art. 161). También existen escuelas rurales, propias de los medios campesinos.

La educación infantil es obligatoria para niños de 4 a 7 años (Art. 105) y se impartiró por "personal femenino especialmente preparado (Art. 106).

La educación primaria elemental es obligatoria para los niños de 7 a 16 años. (Art. 142). A los alumnos de primaria se les proporcionará gratuitamente libros y útiles escolares. (Art. 144).

En cuanto a la duración, la Ley declara que la Primaria tendrá una duración no mayor de seis años (Art. 110) y la Secundaria "un período no mayor de cinco años". (Ârt. 175).

En la educación infantil se permite la coeducación, al decir "se im. partirá en establecimientos comunes a ambos sexos" (Art. 105). El Art. 160 agrega: "La coeducación será establecida en todas las escuelas elementales, siempre que las circunstancias lo requieran. Si asistieran a la escuela mayores de doce años, aquéllas serón unisexuales o funcionarón en forma alterna".

La educación primaria es gratuita; en la Secundaria, la Constitución establece que tendrá tendencia $\alpha$ la gratuidad, conforme ya hemos visto. A este respecto, el Art. 149 dispone que los colegios particulares tendrán becas en número equivalente al $7 \%$ "de su asistencia media, cuando menos".

Las escuelas primarias se dividen en urbanas y rurales, según los casos (Art. 119), y uno de sus principales fines será la "cultura general", los elementos de enseñanza técnica, sin referencia a oficio determinado" (Art. 110).

En cuanto a los idiomas aborígenes, la Ley sin desconocerlos, dispone que la enseñanza tendró como "fin capital, el aprendizaje del castellano y los hábitos de vida civilizada". (Arts. 1 y 2). No obstante esto, cuando predominan las lenguas indígenas, éstas se usarán "como medios de iniciación en la cultura". (Art. 123). Cuando la mayoría sólo posea un idioma nativo, agrega 'la enseñanza será dada en éste, procediéndose por medios pedagógicos a la más pronta castellanización del aborigen". (Art. 124). La finalidad de estas disposiciones es, mediante la educación, incorporar al indígena a la civilización occidental, uno de cuyos vehículos es el idioma castellano. Por eso el Art. 127 declara que no hay escuelas "para indígenas por razón de su raza". Luego en el Art. 128 ordena que el indígena sea educado "por preceptores que conozcan su idioma" sin sacarlo de su pueblo o región.

El Plan de Educación Nacional aprobado por Decreto Supremo de 13 de enero de 1950, abarca toda la enseñanza mediante el desarrollo de las energías espirituales, físicas y materiales del pueblo peruano. Reco- 
noce la trascendencia e importancia de los valores espirituales y morales y los coloca como una de las bases en que se apoya el Plan.

Para la realización de este Plan y como su fundamento económico, se ha creado un Fondo de Educación Nacional con rentas específicas destinado a la construcción de locales escolares en toda la República. Fn pocos años se han construído muchas Unidades Escolares de hombres y de mujeres en las principales ciudades del país, escuelas pre-vocacionales, escuelas normales, escuelas primarias $y$ colegios militares. Se han transformado también las sedes donde anteriormente se impartía enseñan$z a$, pasando de locales inapropiados $\mathrm{y}$ anticuados a espléndidas construcciones, con todos los adelantos modernos. Indudablemente que en cuanto a locales para todos los grados de la enseñanza primaria, secundaria y superior (excepto universitaria), se ha ganado enormemente en estos últimos años, gracias a este Fondo Escolar.

Además de la Ley Orgánica, existen en el Ramo de Educación Pública las siguientes disposiciones legales que forvorecen a la familia bien constituida:

El Decreto Supremo de 31 de julio de 1941, que concede indemnización por familia numerosa en el Magisterio Nacional, exigiéndose como requisito la partida de matrimonio y la de nacimiento o bautismo de los hijos legítimos.

El Decreto Supremo de 20 de enero de 1946, que establece como requisito para el cargo de Inspector de Educación, el ser peruano de nacimiento y casado.

La Resolución Ministerial de 7 de febrero de 1946 concede los servicios de Asistencia de la Mutualista Magisterial a los familiares del asociado. El Decreto Supremo de 28 de mayo de 1946, refiriéndose a los servicios gratuitos proporcionados por la Asociación Mutualista Magisterial, establece que "El servicio de hospitalización será extensivo a la cónyuge e hijos legítimos menores de edad".

El Decreto Supremo de 28 de mayo de 1946 se refiere a la atención médica $\alpha$ las asociadas de la Mutualista Magisterial y en su Art. $1^{\circ}$ establece que: "La A. M. M. contribuiró a los gastos de alumbramiento de la cónyuge de sus asociados, debiendo presentar la partida que acredite que el hijo es legítimo".

El Decreto Supremo de 9 de octubre de 1947, ampliando la asistencia hospitalaria a los maestros, agrega que también "proporcionará el servicio de hospitalización a los cónyuges de sus asociados e hijos legítimos menores". El Decreto Supremo de 8 de junio de 1949 aumenta la cuota para gastos de alumbramiento, debiendo "presentar partida que acredite que el alumbramiento se produjo en matrimonio".

La Resolución Ministerial de 28 de enero de 1950 concede préstamos extraordinarios "en caso de fallecimiento de los padres, hijos, hermanos - cónyuge del asociado".

En el Ramo de Salud Pública y Ásistencia Social existen las siguientes disposiciones que tienen finalidad protectora de la familia legítima:

La Ley 8512, de 5 de marzo de 1937 establece el sistema de casas adjudicadas mediante el arrendamiento-venta. En su Art. 3: "En caso de fallecimiento del adjudicatario jefe de familia, y cualquiera que sea el nú- 
mero de las cuotas mensuales abonadas, concluiró la obligación de pagar el arrendamiento mensual y la casa adjudicada quedará de propiedad definitiva de la viuda e hijos".

El Decreto Supremo de 9 de marzo de 1937, reglamentando esta ley en su Art. 2', inc. c), exige, para conceder la casa, "Tener bajo su guarda dos o más hijos menores de edad y familia legalmente constituída".

La Resolución Ministerial de 14 de abril de 1941, que contiene el Reglamento de ocupación y permanencia del Cuarto Barrio Obrero, exige acreditar la "condición sanitaria, moral y económica del postulante y de su formilia".

El Decreto Supremo de 15 de julio de 1947, dando normas para la distribución de las casas del Barrio Rural de Piedra Liza, en su Art. 10, inc. b), exige "ser obreio casado o viudo".

La Ley 11.854, de 17 de julio de 1952, que ordena la entrega en propiedad de las casas de los Barrios Obreros y Fiscales, exige las mismas condiciones de la ley 8512, es decir tener familia legalmente constituída.

El Decreto Supremo de 24 de marzo de 1952, reglamentando la Ley 11.672, que crea el Fondo de Salud y Bienestar Social, en su Art. 26, inc. c), exige "certificado de matrimonio o viudedad".

El Decreto Supremo de 2 de noviembre de 1953, que es el Reglamento complementario para las viviendas del Fondo, en su Art. 10 "Para los efectos de la adjudicación de vivienda, se exige lo indicado en el Art. $26^{\circ}$ del reglamento de la Ley 11.672, o sea, certificado de matrimonio o viudedad".

En el Seguro Social del Empleado, creado por Ley 10.902 se dictó con fecha 30 de diciembre de 1949 la Ley 11.241, de ampliación de prestaciones, y en su Art. $4^{\circ}$ dice: "Para atender a los gastos de asistencia obstétrica de la cónyuge recibirán los asegurados una asignación de S|. 500.00, cualesquiera que fueren las condiciones del parto". En el artículo $1^{\circ}$ crea el "Riesgo de muerte: Ásignación equivalente al monto de dos sueldos pagaderos al cónyuge o los hijos... etc."

En el Ramo de Justicia existen las siguientes disposiciones:

El Decreto Supremo de 29 de mayo de 1951, concede Bonificación por tiempo de servicios y familia numerosa, a los empleados públicos.

La Resolución Ministerial de 4 de octubre de 1951 da normas reglamentarias del anterior Decreto Supremo y en su Art. $11^{\circ}$ dice: 'Para tener derecho a gozar de bonificación por familia, los empleados deben presentar individualmente una solicitud al Ministerio respectivo, acompañando su partida de matrimonio y la de nacimiento o de bautismo legaiizada, de sus hijos legítimos".

La Resolución Ministerial de 15 de junio de 1954 contiene normas complementarias sobre bonificación por familia y en su Art. 19 dice: "En los casos de legitimación por subsiguiente matrimonio producido con posterioridad $\alpha$ l $1^{\circ}$ de enero de 1952 en que se acordó el beneficio referido, sólo procede abonar la bonificación por familia numerosa a partir de la fecha de la celebración del matrimonio legal".

En el Ramo de Gobiemo, la ley 10.792, de 3 de febrero de 1947, es- 
tablece el Seguro Social Antituberculoso y en su Art. $3^{\circ}$ concede este beneficio "al personal asegurado, a sus esposas e hijos menores de 16 años". En el Art. $4^{\circ}$ concede una pensión base del $60 \%$ al asegurado y $10 \%$ por la mujer y cada hijo menor de 16 años". En su Art. $6^{\circ}$ dice que "El Seguro Social Familiar otorgará a la esposa e hijos menores de 16 años... etc.".

La Resolución Ministerial de 15 de mayo de 1950 concede el derecho de viajar por cuenta del Estado, a las autoridades políticas en unión de sus respectivas esposas e hijas solteras e hijos menores de edad.

En el Ramo de Relaciones Exteriores existen las siguientes disposiciones:

El Decreto Supremo de 16 de febrero de 1950 acuerda franquicias $y$ privilegios al personal de las Misiones Diplomáticas y en su Art. 18, inciso c), dice: "Se exonera del pago de impuestos a los pasajes que adquiera el diplomático en función de su cargo para sí, su esposa, hijas solteras e hijos solteros menores de edad".

La Ley 11.602, de 14 de marzo de 1951, restablece el Pasaporte Diplomático y en su Art. $2^{\circ}$ otorga derecho a este pasaporte a "las esposas, hijas solteras e hijos varones menores de edad".

En el Reglamento del Servicio Diplomático del Perú (Decreto Supremo de 22 de julio de 1953) se reconoce que "Los estudios que cursen los hijos de los funcionarios del Servicio Exterior, cuando sus padres se encuentren prestando servicios en el extranjero, cualquiera que sea su grado y naturaleza, tendrán validez oficial en el Perú". Tales son las leyes, Reglamentos y Resoluciones Supremas que, en diversas formas, acuerdan apoyo a la familia legalmente constituída. 